\title{
The demonstration of immunoglobulin in the metrial gland cells of the rat placenta
}

\author{
D. Bulmer and Sandra Peel \\ Human Morphology, Faculty of Medicine, University of Southampton, \\ Southampton SO9 3TU, U.K.
}

The large, frequently binucleate granulated cells of the metrial gland of the pregnant rat uterus have been the subject of interest for many years. They have been shown to contain glycogen (Bridgman, 1948), and their cytoplasmic granules are characterized by a diastase-fast periodic acid-Schiff reaction (Wislocki, Weiss, Burgos \& Ellis, 1957) and a high content of acid hydrolases (Bulmer, 1968). A variety of functions has been attributed to them, including the provision of nutrient to the developing embryo (Selye \& McKeown, 1935), the liberation of a holocrine secretion facilitating disruption of the muscle coat during the expansion of the uterine wall (Bloch, 1964), and the production of relaxin (Velardo, Dawson, Olsen \& Hisaw, 1953; Dallenbach-Hellweg, Battista \& Dallenbach, 1965); none of these, however, has been proven or considered generally acceptable.

The granulated metrial gland cells are generally believed to arise in situ from mesenchymal cells (Baker, 1948). On the basis of light microscope studies, Smith (1966) suggested that the metrial gland cells of the mouse may be derived from a cell of the lymphocytic series, but this view has not been supported by subsequent workers (Larkin \& Schultz, 1968; Larkin \& Cardell, 1971). However, recent electron microscope findings (Peel \& Bulmer, 1976) have supported Smith's opinion. On morphological grounds, cell types can be recognized in the metrial gland which show intermediate stages from a cell identical in appearance with a small lymphocyte through to a characteristic granulated metrial gland cell. The presence of all the precursor stages up to Day 18 of pregnancy suggests that differentiation of metrial gland cells continues at least until this time. It appeared, therefore, that the metrial gland may be implicated in the immunological reactions of pregnancy and, as a preliminary study, it was decided to investigate the possibility that they may contain an immunoglobulin.

Implantation sites from primigravid Wistar rats at Days 12 and 14 of gestation (spermatozoa in vaginal smear counted as Day 0 ) were fixed in $95 \%$ ethanol for $16-24 \mathrm{~h}$ at $4{ }^{\circ} \mathrm{C}$, subjected to the cold processing technique of Sainte-Marie (1962) and sectioned in paraffin wax. Sections were hydrated at $4^{\circ} \mathrm{C}$ and treated for $30 \mathrm{~min}$ in dilutions, ranging between 1 in 2 and 1 in 132, in phosphate-buffered saline of fluorescein-labelled rabbit anti-rat immunoglobulin (IgG) (heavy and light chain, Wellcome). The sections were washed, with stirring, for $5 \mathrm{~min}$ in each of three changes of phosphate-buffered saline and mounted in a glycerin/phosphate-buffered saline mixture $(1: 1 \mathrm{v} / \mathrm{v})$. Examination by fluorescence microscopy (Zeiss Universal, incident illumination, Phase Neofluar objectives) showed bright apple-green fiuorescence in the mesometrial triangle at Days 12 and 14. Some of the fluorescence was extracellular but much of it was located in the cytoplasm of the metrial gland cells. Parallel phase-contrast microscopy confirmed this localization and showed that much of the fluorescence was in granulated cells; several of the fluorescent cells could be identified as binucleate (Pl. 1, Figs 1 and 2). Fluorescence was largely absent from the decidua basalis, except for occasional scattered cells which were identified as decidual metrial gland cells. Bright fluorescence also occurred in other uterine and placental sites: in the maternal vessels of the placenta, in strands of fibrinoid amongst the inner layers of the metrial gland (Pl. 1, Figs 1 and 2), in the edge of the trophoblast bordering the maternal vessels, in cytoplasmic inclusions in some of the placental giant cells, in the visceral endoderm of the yolk sac and diffusely in connective tissue around the lateral and antimesometrial aspects of the uterine wall. A variable reaction was also obtained in the apices of uterine epithelial cells and in the uterine lumen. The staining characteristics of the metrial gland were detectable after reacting with high dilutions (1 in 132) of fluorescein-labelled anti-IgG. The intensity was similar to that observed in sections of lymph node and spleen processed and stained in parallel. 
Control sections of implantation sites exposed to fluorescein-labelled normal rabbit serum were negative. Fluorescein-labelled rabbit anti-rat albumin (Dynatech) was also used at dilutions up to 1 in 40 . At concentrations below 1 in 8 , fluorescence was absent from the metrial gland although present in blood vessels and in the visceral layer of the yolk sac. At concentrations of 1 in 4 or above, a uniform fluorescence was seen throughout the decidua and the cells and connective tissue of the metrial gland, but the cells were not outstandingly bright. The metrial gland cell reaction with fluorescein-labelled anti-IgG was partly or completely blocked by previous or coincident exposure to non-fluorescent anti-IgG (Dynatech) but not by previous exposure to normal rabbit serum; the degree of block appeared to be related to the concentration of non-fluorescent anti-IgG employed. It was not possible to block the staining due to fluorescent anti-albumin, even with undiluted nonfluorescent anti-IgG.

The observations indicate that cells in the rat metrial gland, including many of the granulated cells, show a strong reaction with fluorescent anti-IgG. The presence of immunoglobulin in the metrial gland cells may be due to its synthesis in situ or to endocytosis of immunoglobulin produced elsewhere, though the absence of any evidence of marked endocytotic activity at the ultrastructural level suggests the former. The function of immunoglobulin in the metrial gland can only be a matter of speculation at this stage. However, the likelihood that the metrial gland cells are derived from B lymphocytes extravasated from the uterine vessels and that they produce and probably secrete an immunoglobulin is obviously of considerable relevance to the immunological problems associated with pregnancy (see Howe, 1975; Johnson, 1975). The metrial gland cells, distributed around the arteriolar channels supplying the placenta and lying in the intercellular spaces of the mesometrium and decidua basalis, appear topographically to be well placed to transmit a secretion such as a blocking antibody to the trophoblast (Faulk, Trenchev, Dorling \& Holborow, 1975). There is morphological evidence both of granule release (Larkin, 1971) and of the passage of entire cells into the maternal vessels (Bridgman, 1948). It is possible that the characteristic granules, with their content of lysosomal enzymes, are concerned in the release of the immunoglobulin. Further study must be devoted to more precise cytological localization of the immunoglobulin, to the origin and nature of the lymphocyte precursors, and to variations in different immunological categories of pregnancy.

\section{References}

BAKER, B.L. (1948) Histochemical reactions in the metrial gland of the rat during pregnancy and lactation. Proc. Soc. exp. Biol. Med. 68, 492-496.

BLoch, S. (1964) Die Glandula myometrialis im Uterus der Maus. Acta anat. 56, 103-119.

Bridgman, J. (1948) A morphological study of the development of placenta of the rat. J. Morph. 83, $61-85,195-223$

Bulmer, D. (1968) Further studies on the granulated metrial gland cells of the pregnant rat. J. Anat. 103, 479-489.

Dallenbach-Hellweg, G., Battista, J.V. \& DallenBACH, F.D. (1965) Immunohistological and histochemical localization of relaxin in the metrial gland of the pregnant rat. Am.J. Anat. 117, 433-450.

Faulk, P., Trenchev, P., Dorling, J. \& Holborow, J. (1975) Antigens on post-implantation placentae. In Immunobiology of Trophoblast, pp. 113-125. Eds R. G. Edwards, C. W. S. Howe \& M. H. Johnson. Cambridge University Press.

Howe, C.W.S. (1975) Lymphocyte physiology during pregnancy: in vivo and in vitro studies. In Immunobiology of Trophoblast, pp. 131-146. Eds R. G. Edwards, C. W. S. Howe \& M. H. Johnson. Cambridge University Press.
JoHnson, M.H. (1975) Discussion. In Immunobiology of Trophoblast, pp. 150-151. Eds R. G. Edwards, C. W. S. Howe \& M. H. Johnson. Cambridge University Press.

LARKIN, L.H. (1971) Electron microscopy of granule release in metrial gland cells of the pregnant rat Anat. Rec. 172, 109-126.

LARKIN, L.H. \& CARDELL, R.R. (1971) Differentiation of granulated metrial gland cells in the uterus of the pregnant rat. Am. J. Anat. 132, 241-258.

LARkin, L.H. \& Schultz, R.L. (1968) Histochemical and autoradiographic studies of the formation of the metrial gland in the pregnant rat. Am J. Anat. 122, 607,619 .

Peel, S. \& Bulmer, D. (1976) The fine structure of the rat metrial gland in relation to the origin of the granulated cells. $J$. Anat. (in press).

SAINTE-MARIE, G. (1962) A paraffin embedding technique for studies employing immunofluorescence. J. Histochem. Cytochem. 10, 250-256.

Selye, H. \& McKeown, J. (1935) Studies on the physiology of the maternal placenta of the rat. Proc. $R$. Soc. B 119, 1-31.

SMIH, L.J. (1966) Metrial gland and other glycogen containing cells in the mouse uterus following 
Pl. IT: 1

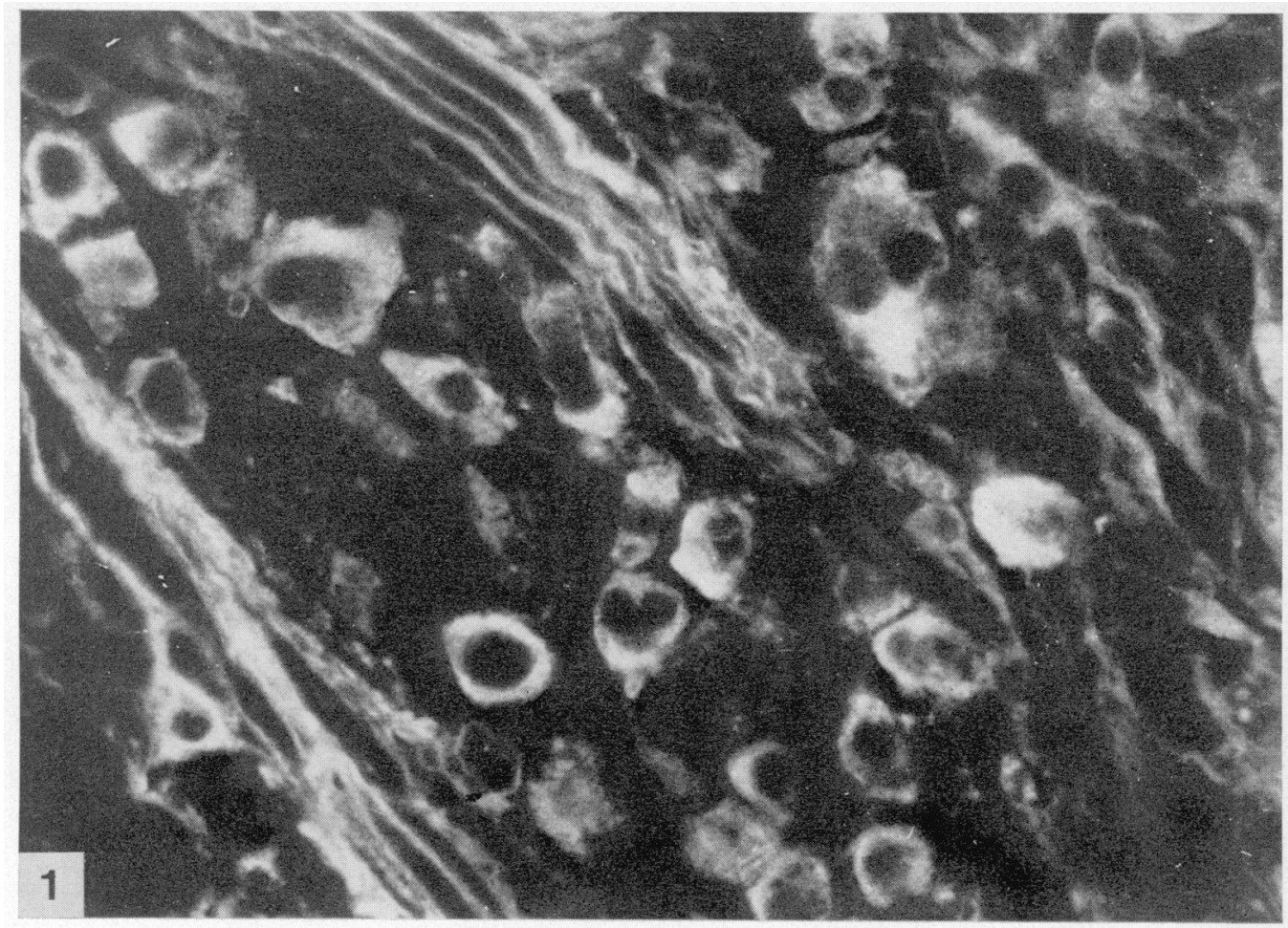

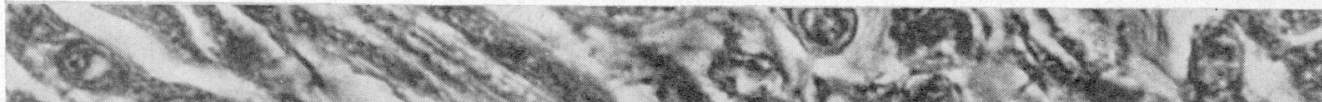

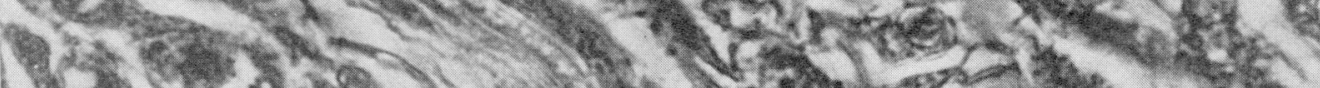

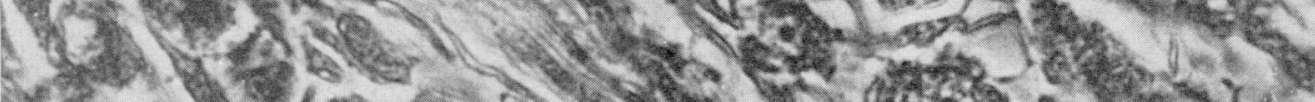

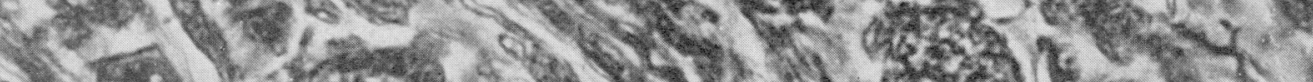

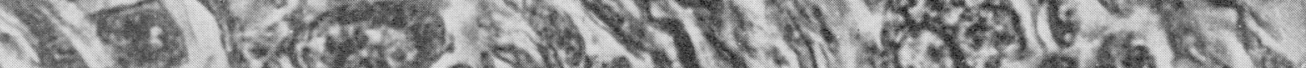

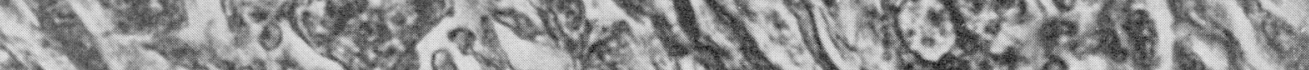

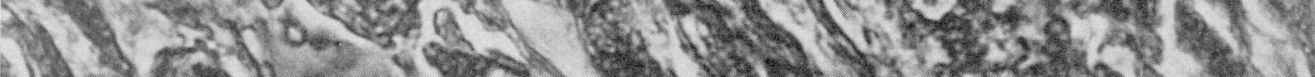

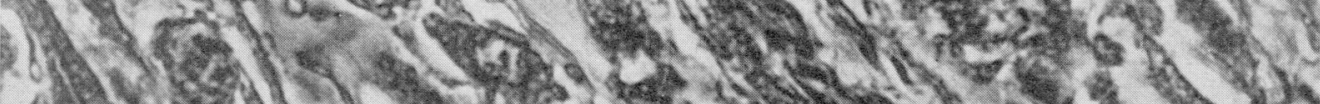

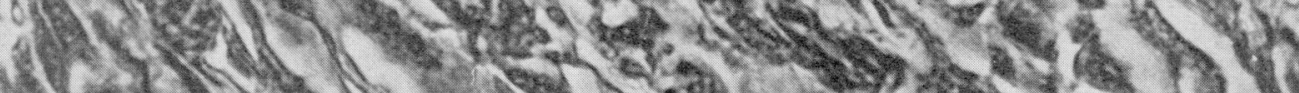

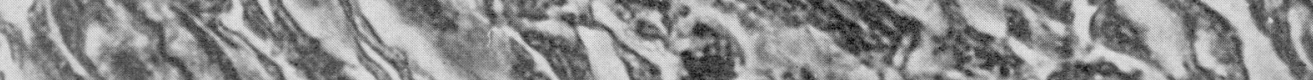

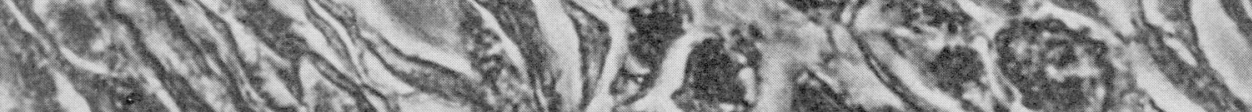

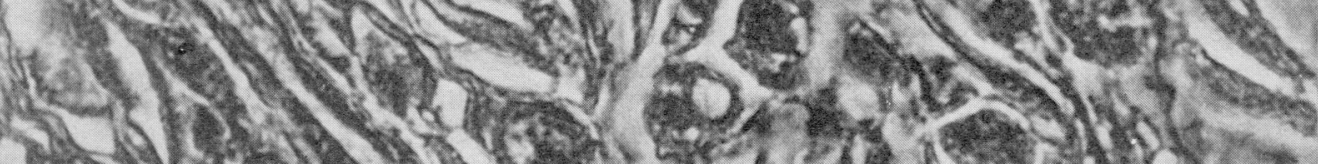
7.5 (5)

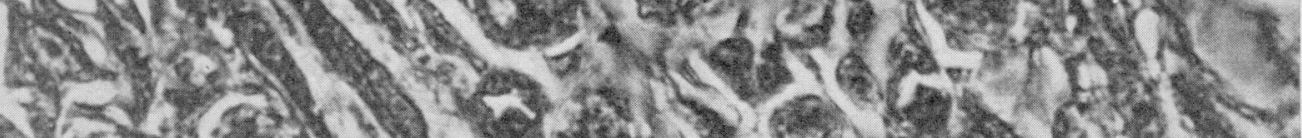
2. 2 m

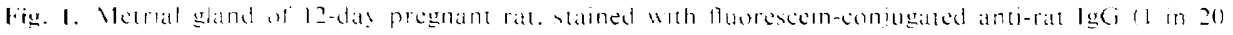

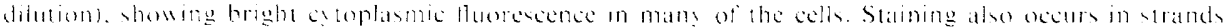

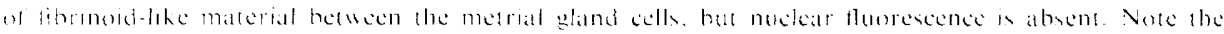
hinuckatco!l (10) righti, xy

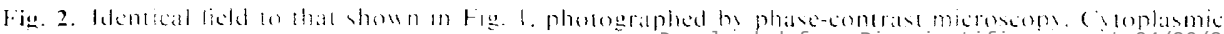

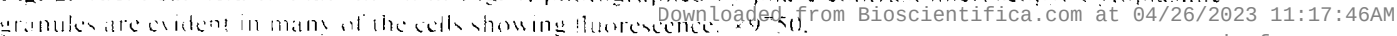


mating and through implantation of the embryo. Am. J. Anat. 119, 15-24.

Velardo, J.T., Dawson, A.B., Olsen, A.G. \& Hisaw, F.L. (1953) Sequence of histological changes in the uterus and vagina of the rat during prolongation of pseudopregnancy associated with the presence of deciduomata. Am. J. Anat. 93, 272-305.

Wislocki, G.B., Weiss, L.P., BuRgos, L.H. \& Ellis, R.A. (1957) The cytology, histochemistry and electron microscopy of the granular cells of the metrial gland of the gravid rat. J. Anat. 91, 130-140.

Received 8 June 1976 